\title{
Design of composite columns based on Eurocode - Comparison between general and simplified methods
}

\author{
H. Unterweger ${ }^{\mathrm{a} *}$, M. Kettler ${ }^{\mathrm{a}}$ \\ anstitute of steel structures, Graz University of Technology, Austria \\ *corresponding author, e-mail address: h.unterweger@tugraz.at
}

\begin{abstract}
In this paper, the results of a comprehensive parametric study for the member capacity of columns subjected to axial forces on the one hand and axial forces plus bending moments on the other hand are presented, considering all relevant types of composite sections: a) concrete encased sections, b) partially encased sections, c) concrete filled rectangular and circular tubes. Different steel grades and concrete strength classes are also considered.
\end{abstract}

Firstly, the different methods of design in the Eurocode are briefly summed up: a) simplified method, based on buckling curves, for axial forces only, b) simplified method, based on a section verification with $2^{\text {nd }}$ order moments, including equivalent geometric imperfections, c) a general method, based on geometrical and material nonlinear calculations with 3D-FEM-models.

In the main part of the paper, the buckling resistance of the columns, based on these 3 methods, are compared, over the whole range of relative slenderness, for different section types, material strengths and type of loading $\left(N, N+M_{z}, N+M_{y}\right)$. Also in the case of columns subjected to bending moments about the strong axis and axial forces, buckling about both axis is studied in detail.

Keywords: column buckling; Eurocode design; design methods.

\section{Design of composite columns based on Eurocode}

In Fig. 1 the different methods for the design of composite columns in EN 1994-1-1 [1] are summed up together with their limits of application. In the following, a brief summary of these methods is presented.

For cases with axial forces only, two simplified methods are available. Only for this loading case the application of the steel buckling curves is possible - see method M1 in Fig. 1.

\subsection{Method M1 - application of steel buckling curves}

The calculation of the relative slenderness is based on Eq. (1), with the plastic resistance of the section $N_{p l, R k}$ - ignoring the individual partial factors for $N_{p l, R d}$ in Eq. (2). Only for concrete filled sections the coefficient 1.0 (instead of 0.85 ) may be used. The elastic critical axial force
$N_{c r}$ is based on Eq. (3) with the effective flexural stiffness $(E I)_{\text {eff }}$ given in Eq. (4) and buckling length $\mathrm{L}$ of the member.

$$
\begin{aligned}
& \bar{\lambda}=\sqrt{\frac{N_{p l, R k}}{N_{c r}}} \\
& N_{p l, R d}=A_{a} f_{y d}+\left(\begin{array}{c}
0.85 \\
1.0
\end{array}\right) A_{c} f_{c d}+A_{s} f_{s d} \\
& N_{c r}=\frac{\pi^{2}(E I)_{e f f}}{L^{2}} \\
& (E I)_{e f f}=E_{a} I_{a}+E_{s} I_{s}+K_{e} E_{c m} I_{c} \\
& \text { with } K_{e}=0.6
\end{aligned}
$$

For the different composite sections the accurate buckling curves are given in Fig. 2, leading to the reduction factor $\chi$, based on EN 1993-1-1 [2]. 


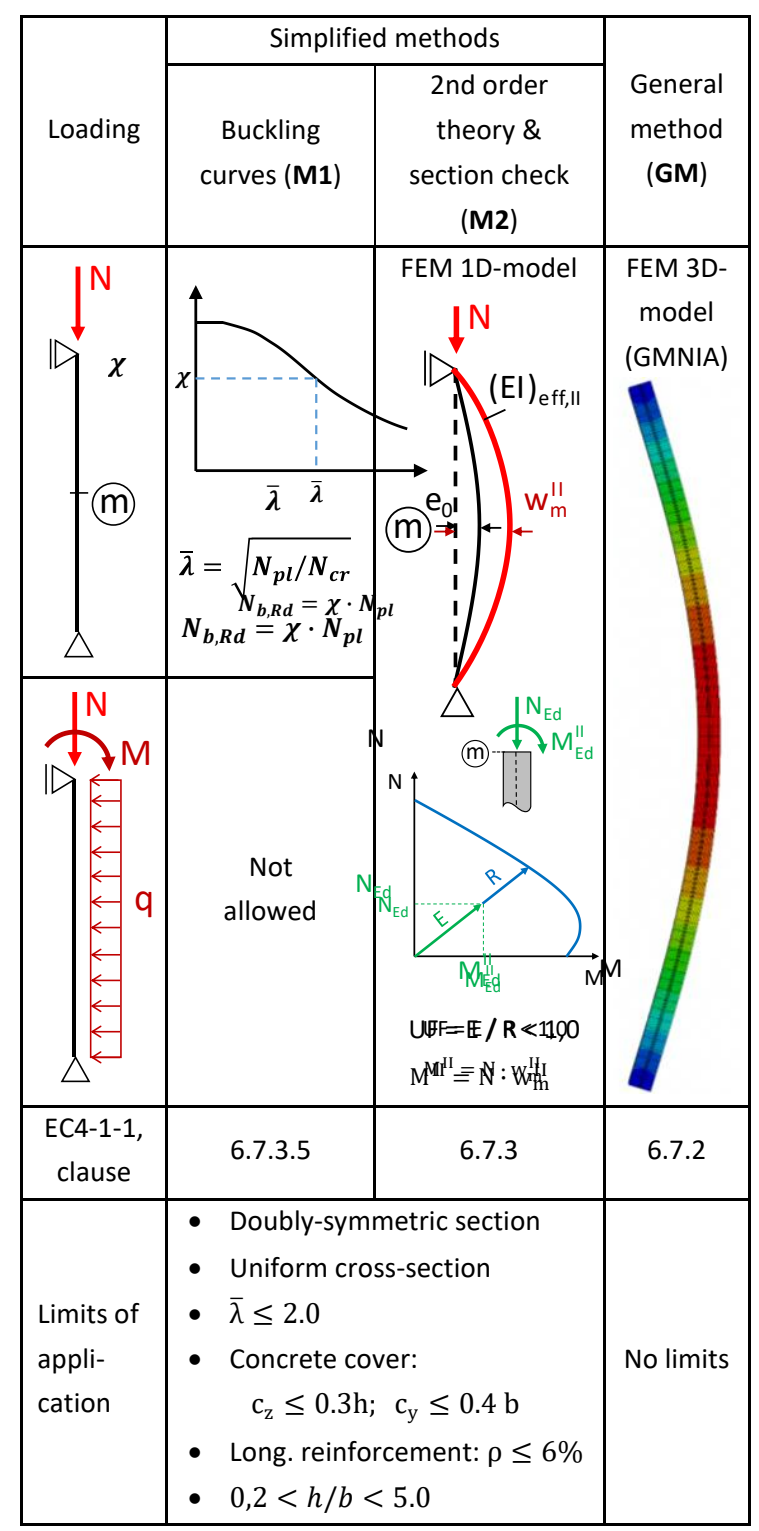

Fig. 1. Calculation procedures for composite columns in EN 1994-1-1

Finally, the buckling capacity $N_{b, R d}$ of the composite column is based on Eq. (5), which also shows the verification procedure.

$$
N_{E d} \leq N_{b, R d}=\chi \cdot N_{p l, R d}
$$

The influence of long-term effects on the buckling capacity $N_{b, R d}$ is considered by reducing the effective flexural stiffness. Now - instead of $E_{c m}-$ an effective modulus of elasticity $E_{c, \text { eff }}$ for the concrete is used, based on Eq. (6). $N_{G, E d}$ is the part of the axial force that is permanent, $\varphi_{t}$ is the creep coefficient, according to EN 1994-1-1 ( $\varphi_{t}$ smaller than in EN 1992-1-1 [3]).

$$
E_{c, e f f}=E_{c m} \frac{1}{1+\frac{N_{G, E d}}{N_{E d}} \varphi_{t}}
$$

\subsection{Method M2 - $2^{\text {nd }}$ order analysis with imperfections}

This method is also available for cases with axial force plus bending (see Fig. 1). The linear elastic analysis is based on the effective stiffness (EI) eff,II calculated with Eq. (7).

$$
\begin{gathered}
(E I)_{\text {eff }, I I}=K_{0}\left(E_{a} I_{a}+E_{s} I_{s}+K_{e, I I} E_{c m} I_{c}\right) \\
\text { with } K_{0}=0.9 \text { and } K_{E, I I}=0.5
\end{gathered}
$$

Individual elastic analysis for both axis of buckling are possible, with additional equivalent geometrical imperfections in the direction of the buckling deformations only, with different amplitudes for each type of composite section (see Fig. 2).

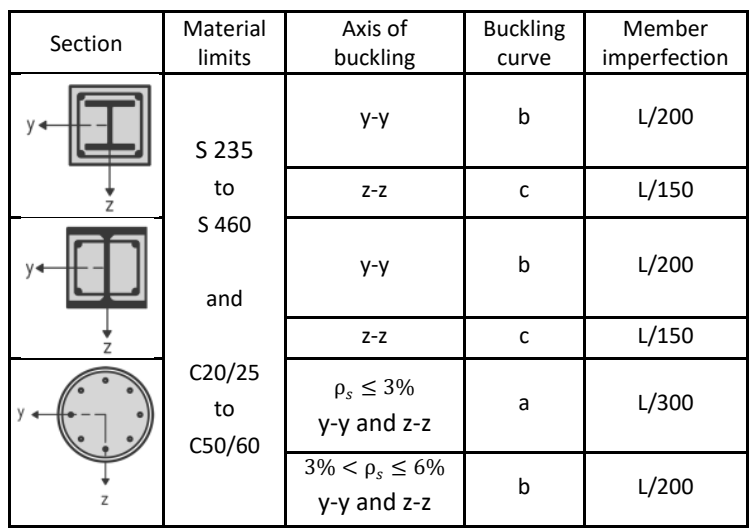

Fig. 2. Investigated cross-sections with equivalent geometric imperfections and corresponding buckling curves (based on [2])

The buckling check is then substituted by a verification of the member capacity, simplified in Fig. 1 in form of an utilization factor UF $\leq 1.0$.

The verification of the member capacity in detail is given in Fig. 3, showing the verification for axial force plus uniaxial bending in Fig. 3a and axial force plus biaxial bending in Fig. $3 b$. Because the member capacity is calculated without any strain limitation (within this study the software INCA2 [4] is used) a reduction factor $\alpha_{M}$ must be used. 


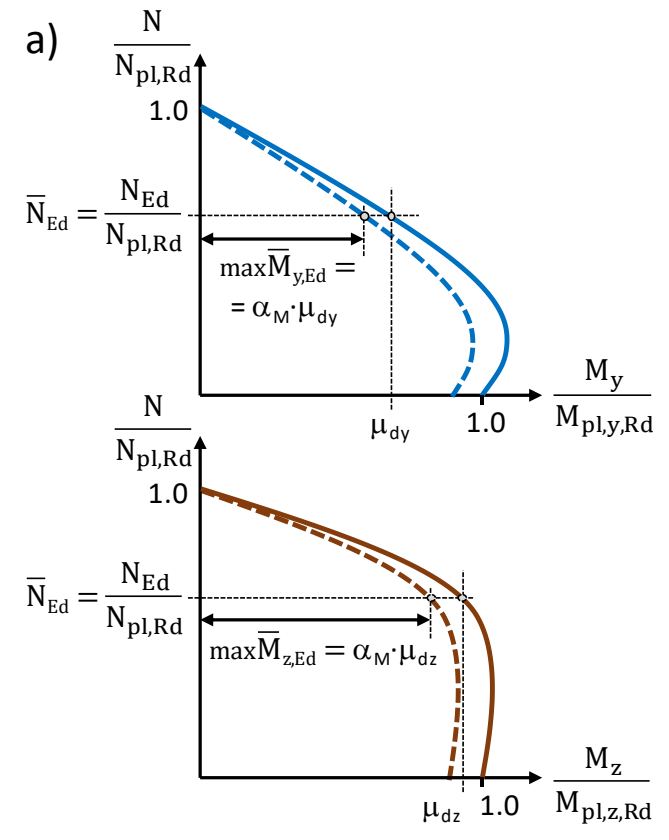

$\alpha_{M}=0.9$ (up to S355); $\alpha_{M}=0.8$ (else)

\begin{tabular}{|l|l|}
\hline$\frac{\mathrm{M}_{\mathrm{y}, \mathrm{Ed}}}{\mu_{\mathrm{dy}} \cdot \mathrm{M}_{\mathrm{pl}, \mathrm{y}, \mathrm{Rd}}} \leq \alpha_{\mathrm{M}}$ & $\frac{\mathrm{M}_{\mathrm{z}, \mathrm{Ed}}}{\mu_{\mathrm{dz}} \cdot \mathrm{M}_{\mathrm{pl}, \mathrm{z}, \mathrm{Rd}}} \leq \alpha_{\mathrm{M}}$ \\
\hline
\end{tabular}

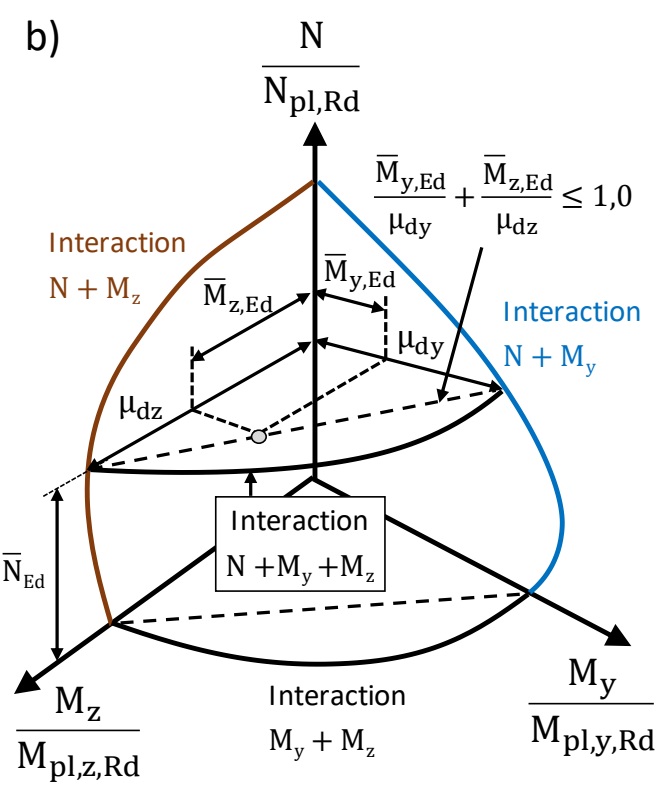

$$
\frac{M_{\mathrm{y}, \mathrm{Ed}}}{\mu_{\mathrm{dy}} \cdot \mathrm{M}_{\mathrm{pl}, \mathrm{y}, \mathrm{Rd}}}+\frac{\mathrm{M}_{\mathrm{z}, \mathrm{Ed}}}{\mu_{\mathrm{dz}} \cdot \mathrm{M}_{\mathrm{pl}, \mathrm{z}, \mathrm{Rd}}} \leq 1,0
$$

Fig. 3. Procedure of the design check for compression and mono-axial or bi-axial bending (method M2)

\subsection{General method}

The general method has no application limits. It is also applicable for non-symmetric sections and members with non-uniform sections. The global analysis on a 3D-model is a geometric and material nonlinear analysis with imperfections (GMNIA) and must include $2^{\text {nd }}$ order effects, imperfections (geometric imp. and residual stresses), cracking of concrete and long term effects of concrete (creep and shrinkage). For the global analysis mean values for the material parameters must be used. The tensile strength of the concrete should be neglected. Full composite action may be assumed in the interface between concrete and steel components. Unfortunately, in Eurocode no mean values for structural steel are given.

In addition to the global analysis, which results in a load amplification factor $\lambda_{\text {ult }}$ also the section behaviour of the critical section must be considered (Fig. 4) to calculate the overall partial factor $\gamma_{R}$ for the resistance. Finally, in the verification $\lambda_{u l t}$ must be higher than $\gamma_{R}$.

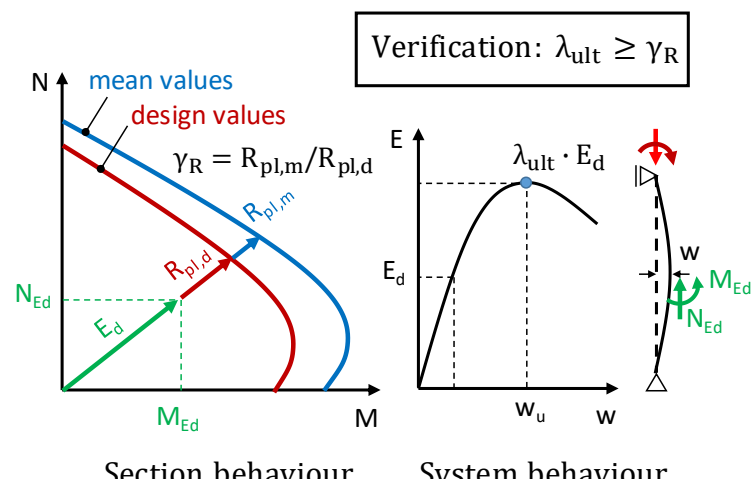

Fig. 4. Procedure of the design check according to the general design method

Within this study, the global analysis were done with the software Abaqus [5], using solid elements of type C3D8R (linear elements with 8 nodes and 1 integration point). For the structural steel component, the fillets are modelled and also the reinforcing bars. Full composite action between all components was assumed. The residual stresses in the structural steel component were modelled directly, with the distributions given in [6]. For the geometric imperfections, the buckling shape of the $1^{\text {st }}$ eigenmode was chosen with a maximum amplitude of $e_{0, \text { geom }}=\mathrm{L} / 1000$.

For structural steel and steel reinforcement a linear elastic, ideal plastic stress-strain curve was used. For the stress-strain curve of the concrete EN 1992-1-1 [3] and Model Code 2010 [7] were chosen.

For the material parameters the following mean and design values were used: 
- S235: $f_{y d}=f_{y k}=235 ; f_{y m}=285 ; E_{a}=$ $210,000 \mathrm{~N} / \mathrm{mm}^{2} ; v=0.3$

- $\quad \mathrm{BSt550:} f_{s d}=478 ; f_{s k}=550 ; f_{s m}=605 ; E_{a}$ $=200,000 \mathrm{~N} / \mathrm{mm}^{2} ; v=0.3$

- Concrete: $f_{c m}=f_{c k}+8 ; f_{c t m}=0.3 \cdot f_{c k}^{0.67} ; E_{c m}$ $=22,000 \cdot\left(f_{\mathrm{cm}} / 10\right)^{0.3} \mathrm{~N} / \mathrm{mm}^{2}$

The cracking of concrete was considered in form of a linear reduction of the tensile stresses, based on the fracture energy $G_{F}$, with $G_{F}=$ $73 \cdot f_{c m}^{0.18}$ [7]. The effect of creep was considered, as for the simplified methods, in form of a reduced effective modulus of elasticity $E_{c, \text { eff }}$, see Eq. (6).

Within the global analyses presented in this paper, the following steps were made: i) linear buckling analyses for calculation of the assumed imperfection shape, ii) application of residual stresses, strains due to shrinkage (only for study of long term behaviour) and full axial force $\mathrm{N}$, iii) nonlinear increase of bending moment.

In addition, other possible load paths were verified (simultaneous increase of axial force plus bending, firstly application of full bending moment), leading to nearly the same ultimate loads.

\section{Comparison of results - axial force $N$ only}

For all different types of composite sections (concrete encased, partially encased, concrete filled rectangular and circular tubes), a comparison of the results of the two simplified methods was done. On the one hand for short term behaviour and on the other hand for long term behaviour. For the latter, extreme values in view of practical applications - were assumed $\left(N_{G, E d} / N_{E d}=0.75\right)$, with $t_{o}=28$ days and a creep coefficient $\varphi_{t}=\varphi(\infty, 28)$ based on EN 1994-1-1.

Due to space limitations, only one representative section type, a partially encased section, is presented in Fig. 5. All other section types are presented in detail in $[8,9]$. The results are given in form of the reduction factor $\chi$ for different combinations of material strength, plotted over the relative slenderness $\bar{\lambda}$ also given for $\bar{\lambda}>2.0$ which is outside the scope of the code (see Fig. 1). In Fig. 5a the results for the short term behaviour are given and in Fig. $5 b$ for the long term behaviour.

For method M1 each material combination leads to the same load capacity (called EC4b.curve c). It can be seen that method M2, based on an elastic $2^{\text {nd }}$ order analysis, leads in general to lower ultimate loads. Also for this method M2 the material combination has nearly no influence on the reduction factor $\chi$. For low relative slenderness of about $0.5<\bar{\lambda}<1.0$ the differences are least. For the long term behaviour method M2 leads to increased ultimate loads, leading sometimes to higher capacities than based on method M1.
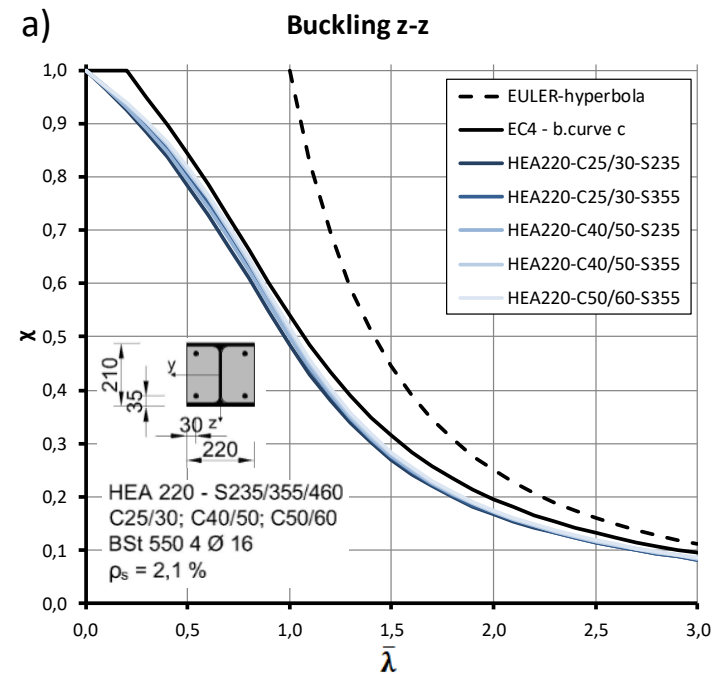

b) Buckling z-z

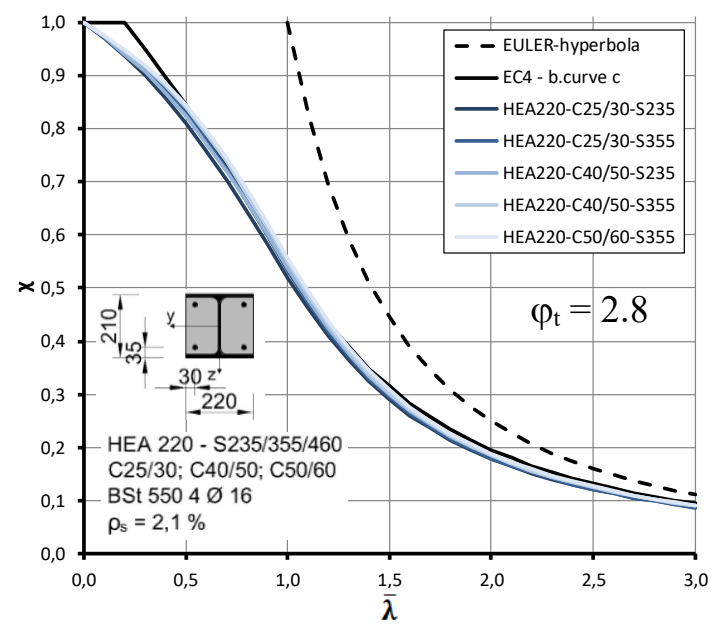

Fig. 5. Comparison of the two simplified design methods for compression (M1 and M2) and for different material combinations of a partially concrete encased HEA 220 section; a) without creep, b) including creep effects for $N_{G, E d} / N_{E d}=0.75$ and $\varphi_{\mathrm{t}}=2.8$

As summary, the differences of both simplified methods are small and the simpler one (M1), from a practical point of view, leads in general to higher ultimate loads. 


\section{Compression and uniaxial bending ( $N$ $\left.+M_{y}\right)$ - accurate buckling checks}

For structural steel sections in case of loading due to compression and uniaxial bending, a simplified buckling verification for buckling about the z-axis is allowed [2], ignoring the bending moment $M_{y}$. This is called ,verification c" in Fig. 6 and allows the application of both simplified methods. The correct application of EN 1994-1-1 for a buckling verification about the $\mathrm{z}$-axis leads to biaxial bending, because of geometric imperfections in y-direction leading to additional bending moments $M_{z}$ - here called „verification b“.

The buckling verification about the y-axis, called ,verification a“, leads to uniaxial bending $\left(N+M_{y}\right)$ only. In Fig. 6 the ultimate capacities for these different buckling verifications are again shown for an example of a partially encased section (similar behavior also for other section types) if method M2 is applied, for different combinations of $N_{E d}$ and $M_{y, E d}$. It can be seen that a buckling verification about the z-axis, ignoring the bending moment $M_{y}$ (verification $\mathrm{a}+\mathrm{c}$ ), leads to unacceptable member capacities compared to the correct application (verification $\mathrm{b}+\mathrm{c}$ ), highlighted by the shaded area.

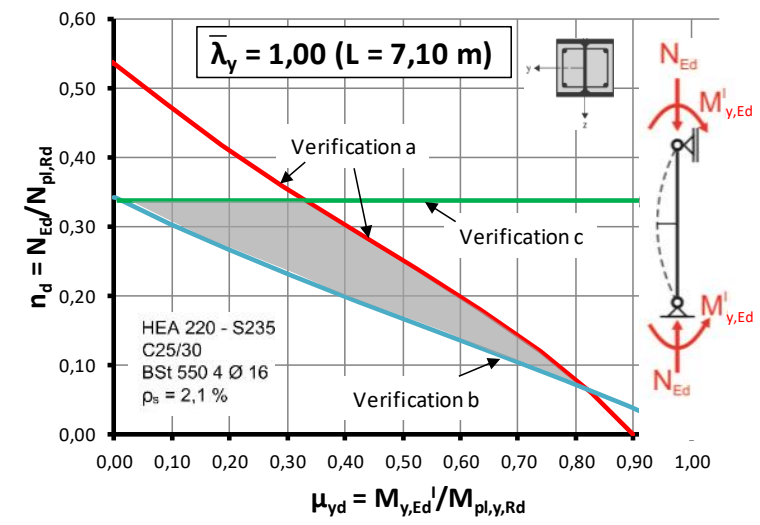

Fig. 6. Column subjected to $N$ plus $M_{y}$; Presentation of the individual buckling checks

As a summary, for composite columns the buckling verification about the $\mathrm{z}$-axis must always include the bending moment $M_{y}$.

\section{Application of the global method and comparison with method M2 - loading $N$ $+M_{y}$}

Also for this comparison only the results for short term behaviour and the section type partially encased and concrete filled circular tubes are presented in Fig. 7 and Fig. 8, with assumed constant moment along the member. The results for long term behaviour and other section types and also for loading $N+M_{z}$ are given in $[8,9]$.

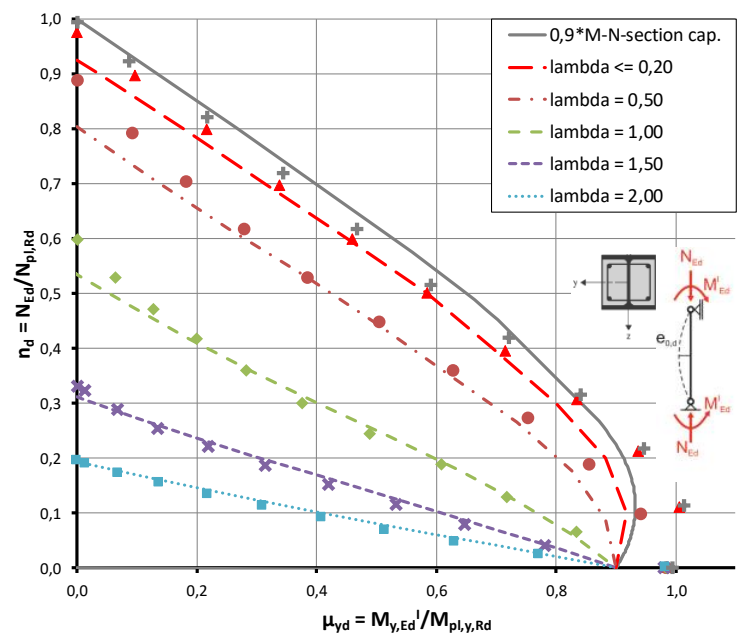

Fig. 7. Section HEA220, C25/30, S235 - Resistance curves for buckling about strong axis under $N$ $+M_{y}$ without creep effects

The results, based on the global method and the simplified method M2 are plotted in form of an interaction diagram, based on the $1^{\text {st }}$ order moments. The results are given for four different slenderness values $(\bar{\lambda}=0.5 ; 1.0 ; 1.5 ; 2.0)$ and for the borderline case of the section capacity only $(\bar{\lambda} \leq 0.2)$. The plotted curves represent method M2, whereas dots represent results of the general method.

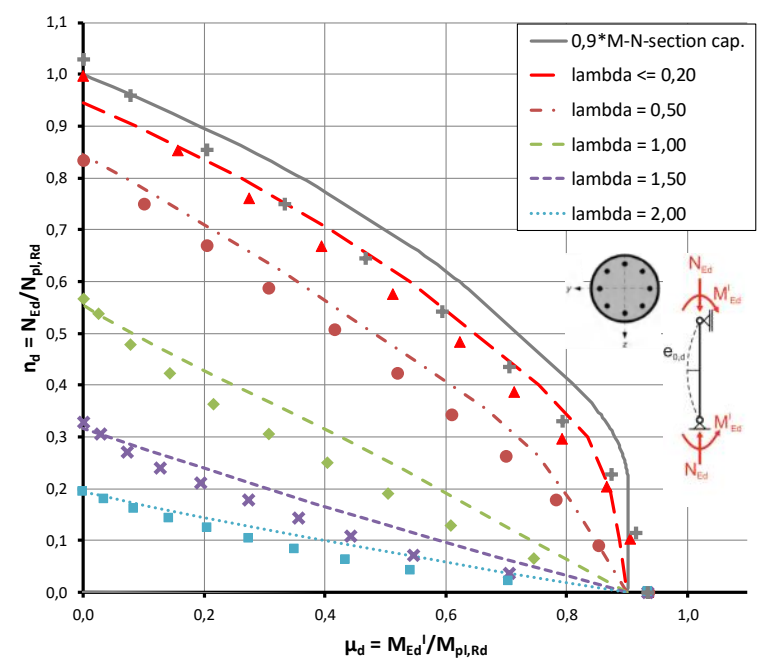

Fig. 8. Section CHS355,6x10, C25/30, S235 Resistance curves for $\rho_{s}=5.0 \%$ and $e_{0, d}$ acc. to buckling curve b for M2 under $N+M-$ without creep effects 
For the partially encased section both methods give nearly the same member capacity, shown in Fig. 7. For the concrete filled circular tube (Fig. 8) the simplified method overestimates the loading capacity of the general method.

The application of buckling curve $b$ for the concrete filled circular tube in the simplified method M2 seems to be unsafe. If buckling curve $\mathrm{c}$ is assumed the results of both methods are nearly the same.

If also long term behaviour is assumed the differences between the results of both methods increase, with in general higher capacities based on the simplified method M2.

As an example for this issue the results including the long-term behavior are given in Fig. 9 and can be compared with the results in Fig. 7 without any long-term effects. In Fig. 9 also for the general method the results are given for: i) only creep effects (GMNIA C), ii) creep and shrinkage effects (GMNIA $\mathrm{C}+\mathrm{S}$ ).

\section{Conclusions}

The comprehensive study of the different design methods for composite columns in Eurocode, summed up in this paper, showed the following results for the studied double symmetric sections (concrete encased sections, partially encased sections, concrete filled rectangular and circular tubes):

- For columns with uniaxial bending $\left(N+M_{y}\right)$ the buckling verification about the z-axis must always include the bending moment $M_{y}$. A simplified procedure for buckling about the zaxis with axial force $N$ only, will lead to an unacceptable high ultimate load capacity.

- For columns in compression (axial force $N$ only) the simplest buckling verification based on the buckling curves for steel sections (method M1) leads to very similar, predominantly higher results than the verification based on a $2^{\text {nd }}$ order analysis with imperfections (method M2).

- For columns with compression plus uniaxial bending $\left(N+M_{y}\right.$ or $\left.N+M_{z}\right)$ the general method nearly always leads to lower ultimate loads than the simplified method M2. From a practical point of view the application of the general method seems therefore only useful if the limits of application of the simplified methods are not fulfilled.

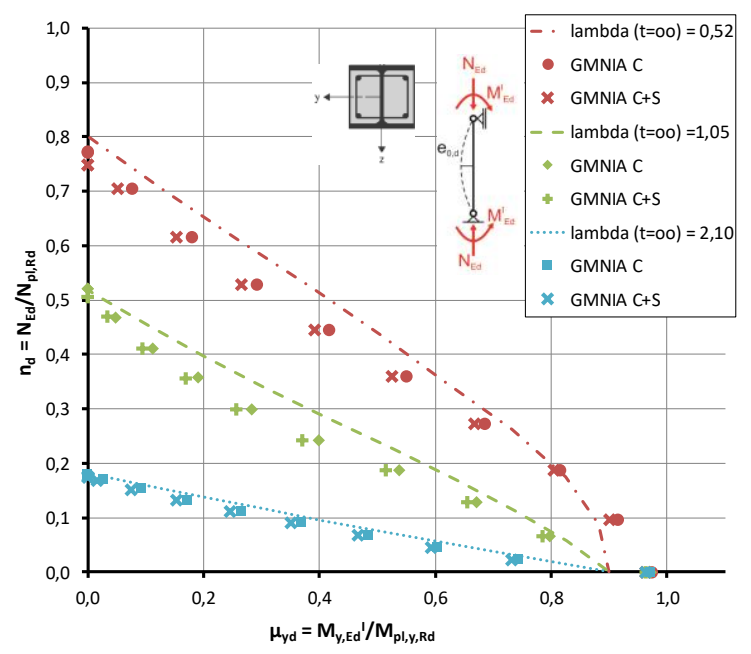

Fig. 9. Section HEA220, C25/30, S235 - Resistance curves for buckling about strong axis under $N$ $+M_{y}$ including long-term effects with $N_{G, E d} / N_{E d}=0.60$ and $\varphi_{\mathrm{t}}=2.8$

\section{References}

[1] European Standard EN 1994-1-1, Design of composite steel and concrete structures - Part 11: General rules and rules for buildings. CEN, Brüssel, 2010.

[2] European Standard EN 1993-1-1, Design of steel structures - part 1-1: General rules and rules for buildings. CEN, Brüssel, 2011.

[3] European Standard EN 1992-1-1, Design of concrete structures - part 1-1: General rules and rules for buildings. CEN, Brüssel, 2011.

[4] Software INCA2, 2.90, Author: Pfeiffer U. Institut für Massivbau, TU Hamburg-Harburg, 2016.

[5] Dassault Systems, Abaqus v6.10 and Abaqus v6.10 Documentation, USA, 2010.

[6] Kuhlmann U, Feldmann M, Lindner J, Müller C, Stroetmann R. Kommentar zu Eurocode 3 Stahlbau - Band 1. Berlin, Beuth Verlag GmbH, 2014.

[7] Fib, Model Code for Concrete Structures 2010, Berlin, Wilhelm Ernst \& Sohn, 2013.

[8] Sixthofer T. Begutachtung und Vergleich der aktuellen Bemessungsverfahren für Verbundstützen, Masterarbeit, TU Graz, 2016.

[9] Unterweger H, Kettler M. Verbundstützen nach Eurocode 4 - Vergleich zwischen allgemeinem und vereinfachten Bemessungsverfahren. Tagungsband 39. Stahlbauseminar der Hochschule Biberach, 2017 